Communication

\title{
Tribological and Anticorrosion Performance of Electroplated Zinc Based Nanocomposite Coatings
}

\author{
Marcin Klekotka ${ }^{1, *(\mathbb{D})}$, Katarzyna Zielińska ${ }^{2}$, Alicja Stankiewicz ${ }^{2} \mathbb{1}$ and Michal Kuciej ${ }^{3, * \mathbb{C}}$ \\ 1 Institute of Biomedical Engineering, Bialystok University of Technology, Wiejska 45C, \\ 15-351 Bialystok, Poland \\ 2 Coat-It Sp. z o. o., Mościckiego 1, 24-110 Puławy, Poland; katarzyna@coat-it.pl (K.Z.); alicja@coat-it.pl (A.S.) \\ 3 Institute of Mechanical Engineering, Bialystok University of Technology, Wiejska 45C, \\ 15-351 Bialystok, Poland \\ * $\quad$ Correspondence: m.klekotka@pb.edu.pl (M.K.); m.kuciej@pb.edu.pl (M.K.); \\ Tel.: +48-50-0003866 (M.K.); +48-79-0281402 (M.K.)
}

Received: 27 May 2020; Accepted: 22 June 2020; Published: 24 June 2020

\begin{abstract}
This paper presents the results of corrosion and tribological analysis of pure and nanocomposite zinc coatings. Coatings were electroplated using commercially available products—zinc acidic bath and a nanoparticle carrying plating additive. Electrochemical measurements were carried out to compare the anticorrosion performance of coatings. An investigation into the influence of nanoparticles on the mechanical properties was performed. The zinc nanocomposite coating exhibited better wear resistance and higher hardness than the plain zinc coating. The application of confocal laser scanning microscopy (CLSM) allowed the detailed description of friction/wear marks. The electrochemical studies revealed that the introduction of nanoparticles into the coating did not compromise its protective properties - a similar resistance of plain and nanocomposite coatings to corrosion was obtained.
\end{abstract}

Keywords: confocal laser scanning microscopy; fretting corrosion; protective coating; nanocoating; nanocomposite

\section{Introduction}

The electroplating of zinc is an industrial process that is extensively used to protect steel surfaces and enhance their service life. This material is widely employed in the automotive industry to produce brake pipes, brake callipers and power steering components [1]. Zinc electroplating is also used in the production of tanks, armoured personnel carriers and other heavy military vehicles [2]. Steel articles coated by zinc exhibit better corrosion resistance as a result of sacrificial coating protection, known as white rust corrosion. The development of this white rust can be controlled by surface passivation [3], where an additional barrier layer is created. The passivation is a process of dipping a material covered with zinc in a solution containing chromium compounds. The carcinogenic hexavalent chromium is still employed as a key compound in the passivation process. An alternative method of increasing the service life of zinc-coated materials is to include solid particles in a zinc matrix [4,5]. An application of inorganic or organic particles also creates opportunities for the multifunctional modification of zinc coatings. The addition of hard particles such as $\mathrm{SiO}_{2}, \mathrm{TiO}_{2}$ and $\mathrm{CeO}_{2}$, improves coating hardness and wear resistance [6]. Soft particles like PTFE, polystyrene or polymethylmethacrylate can equip zinc coatings with a low coefficient of friction or hydrophobic properties [7]. However, the inclusion of microparticles not only provides various functional properties, but at the same time may cause porous structure and irregularities in the texture. In order to increase coating quality in terms of both anticorrosion and mechanical properties, the microparticles are replaced by nanoparticles. The nanoparticles fill voids in the zinc matrix, providing barrier properties by blocking active sites for 
corrosion initiation [8]. In terms of enhancing mechanical properties, hard nanoparticles dispersed in the coating can hinder the easy movement of dislocations, thus increasing the coating's hardness [9]. To evaluate wear resistance, pin-on-disc and pin-on-flat tribological methods are the most widely used. Anticorrosion features are usually assessed by electrochemical techniques or a salt spray method.

In the present study, the tribological and corrosion behaviour of zinc and composite zinc coatings containing hard nanoparticles were evaluated. Besides traditional tribological methods, confocal laser scanning microscopy (CLSM) was used for the first time to characterise the metallic coatings. To our best knowledge, this was the first successful attempt to produce zinc nanocomposite coatings from commercially available products.

\section{Materials and Methods}

\subsection{Sample Preparation}

Austenitic steel 316L (Table 1) was covered with plain zinc ( $\mathrm{Zn}$ ) and composite zinc coatings containing metal oxide hard nanoparticles $(\mathrm{Zn} / \mathrm{NP})$. Steel samples were prepared in the following steps: 1. sandpaper polishing (from 400 to 1200 grit), 2. rinsing, 3. degreasing with acetone, 4 . alkaline cleaning, 5. rinsing, 6. acid pickling, and 7. rinsing. Coatings were prepared by electrodeposition from an acidic bath of $5 \mathrm{~L}$, containing zinc sulphate as a source of zinc ions, provided by Gateros Plating Ltd. A bath temperature of $20^{\circ} \mathrm{C}$ and current density of $2 \mathrm{~A} / \mathrm{dm}^{2}$ were applied. In the case of zinc nanocomposite coatings, the process parameters were kept the same and, to the $5 \mathrm{~L}$ of standard plating bath, $250 \mathrm{~mL}$ of nanoparticle-containing KA 201 additive provided by Coat-It Sp. z o. o. (Poland) was added. Applying the KA201 additive to prepare plating baths for nanocomposite coatings production allows for the uniform distribution of nanoparticles in a solution without intensive stirring and wetting agents. The coatings' thickness of $20 \pm 2 \mu \mathrm{m}$ were analysed by a gravimetric method. The hardness, roughness, and corrosion and wear resistance of zinc and zinc nanocomposite coatings were tested.

Table 1. Chemical composition of 316L stainless steel (maximum content as a wt. \%).

\begin{tabular}{cccccccccccc}
\hline $\mathbf{F e}$ & $\mathbf{C r}$ & $\mathbf{N i}$ & $\mathbf{M o}$ & $\mathbf{M n}$ & $\mathbf{S i}$ & $\mathbf{C u}$ & $\mathbf{N}$ & $\mathbf{N b}$ & $\mathbf{C}$ & $\mathbf{S}$ & $\mathbf{P}$ \\
\hline Remainder & 18.329 & 11.301 & 2.385 & 2.131 & 0.375 & 0.100 & 0.086 & 0.072 & $<0.020$ & $<0.020$ & $<0.010$ \\
\hline
\end{tabular}

\subsection{Corrosion Tests}

Corrosion resistance tests were performed using the PGP 201 potentiostat (Radiometer Analytical, Lyon, France) and the VoltaMaster 4 software. The measurements were carried out using a three-electrode system in a measuring vessel made of borosilicate glass filled with $70 \mathrm{~cm}^{3}$ of electrolyte $(0.9 \% \mathrm{NaCl})$ at a temperature of $21^{\circ} \mathrm{C}$. A saturated calomel electrode of $\mathrm{Hg} / \mathrm{Hg}_{2} \mathrm{Cl}_{2} / \mathrm{Cl}^{-} \mathrm{REF} 421$ (Radiometer Analytical, Loveland, CO, USA) was the reference electrode, the potential of which-relative to the normal hydrogen electrode-was $+0.244 \mathrm{~V}$. The auxiliary electrode was an XM 140 platinum electrode (Radiometer Analytical, USA) with an area of $8 \mathrm{~mm} \times 8 \mathrm{~mm}$, and the working electrode was a sample. Cylinder-shaped samples with a diameter of $8 \mathrm{~mm}$ were placed in a specially constructed holder that enabled the contact of the sample with the electrolyte from the frontal surface only and simultaneously allowed the sample to connect with the potentiostat. Tests for pitting corrosion resistance began with the determination of the open circuit potential (OCP, EOCP). Then, the research was carried out using the potentiodynamic method, from the potential $\mathrm{E}_{\text {init }}=\mathrm{E}_{\mathrm{OCP}}-100 \mathrm{mV}$. The change in potential occurred in the anode direction at a rate of $3 \mathrm{mV} / \mathrm{s}$. After the maximum value of the measuring range $+2000 \mathrm{mV}$ was reached or anode current density of $1 \mathrm{~mA} / \mathrm{cm}^{2}$ was obtained, the polarization direction was changed. All tests were repeated three times.

\subsection{Tribological Tests}

Tribological studies were carried out using a UMT TriboLab tribometer (Bruker, Billerica, MA, USA), with a ball-on-disc system under dry friction conditions. The duration of each measurement 
was $300 \mathrm{~s}$. A $6 \mathrm{~mm}$ immobile ball made of corundum $\left(\mathrm{Al}_{2} \mathrm{O}_{3}\right)$ was a counterbody. Cylindrical samples, with a diameter of $8 \mathrm{~mm}$, were placed in a special holder attached to the table performing reciprocating motion. The amplitude of the system displacements was $500 \mu \mathrm{m}$. Each measurement was repeated three times. Abrasion resistance of the coatings was tested with the following parameters:

- $\quad$ Normal force $(\mathrm{Fn})=1 \mathrm{~N}$, frequency $(\mathrm{f})=5 \mathrm{~Hz}$;

- $\quad$ Normal force $(\mathrm{Fn})=2 \mathrm{~N}$, frequency $(\mathrm{f})=10 \mathrm{~Hz}$.

\subsection{Microscopy Analysis}

The surfaces of the samples after tribological tests were subjected to microscopic observations using the LEXT OLS4000 confocal microscope (CLSM, Olympus, Tokyo, Japan) with 3D image feature and the scanning electron microscope (SEM) Phenom XL (Phenom-World, Eindhoven, The Netherlands) with the EDS X-ray microanalysis module.

Coating roughness $(R a)$ measurements were made using a LEXT OLS400 confocal microscope. The 3D imaging feature of CLSM was used to measure the volume and depth of wear tracks. The details of the measurement method were described in our previous publication [10]. Microhardness tests were carried out using the Vickers method with a load of 0.9807 N. For statistical purposes, each measurement was repeated ten times.

\section{Results and Discussion}

The coatings were successfully produced from a commercially available zinc bath and nanoparticle-containing additive. The results of the corrosion resistance tests of the pure zinc and $\mathrm{Zn} / \mathrm{NP}$ coatings are presented in Figure 1 and summarised in Table 2.

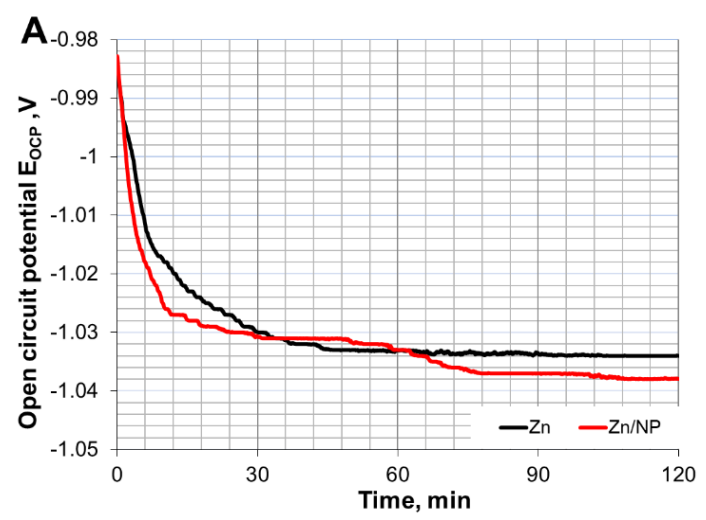

(A)

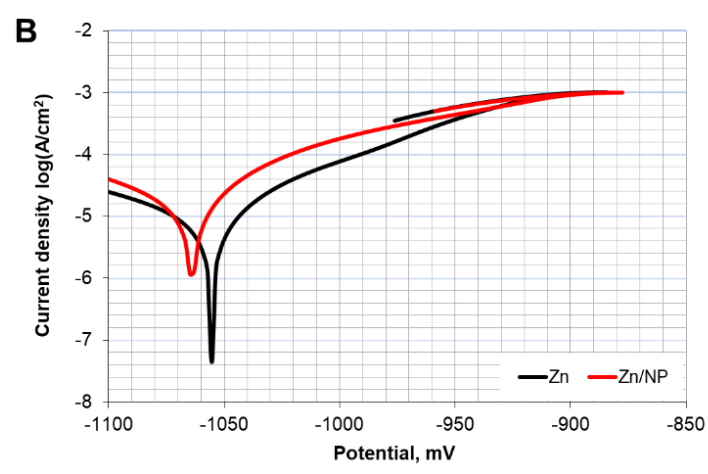

(B)

Figure 1. Electrochemical results of corrosion tests: (A) open circuit potential curves; (B) anodic polarization curves.

Table 2. Main parameters of corrosion tests.

\begin{tabular}{ccccccc}
\hline Sample & $\mathbf{E}_{\mathbf{O C P}}(\mathbf{m V})$ & $\mathbf{E}_{\mathbf{c o r r}}(\mathbf{m V})$ & $\mathbf{R p}\left(\boldsymbol{\Omega} \cdot \mathbf{c m}^{\mathbf{2}}\right)$ & $\mathbf{B}_{\mathbf{a}}(\mathbf{m V})$ & $\mathbf{B}_{\mathbf{c}}(\mathbf{m V})$ & $\mathbf{I}_{\text {corr }}\left(\boldsymbol{\mu A} / \mathbf{c m}^{\mathbf{2}}\right)$ \\
\hline $\mathbf{Z n}$ & $-1034 \pm 0.8$ & $-1041 \pm 1.2$ & $1089 \pm 321$ & $45.4 \pm 3.5$ & $79.7 \pm 14.6$ & $12.1 \pm 2.5$ \\
$\mathbf{Z n} / \mathbf{N P}$ & $-1040 \pm 5.6$ & $-1052 \pm 8.3$ & $1117 \pm 309$ & $47.1 \pm 3.0$ & $96.4 \pm 10.1$ & $12.9 \pm 2.2$ \\
\hline
\end{tabular}

$\mathrm{E}_{\mathrm{OCP}}$ : open circuit potential, $\mathrm{E}_{\text {corr }}$ : corrosion potential, $\mathrm{Rp}$ : polarization resistance, $\mathrm{B}_{\mathrm{a}} \mathrm{B}_{\mathrm{c}}$ : Tafel slopes $\mathrm{I}_{\text {corr }}$ : density of corrosion current.

Low open-circuit potential values suggest that sample surfaces are particularly susceptible to oxidation processes. This is usual for zinc layers, which act as sacrificial coatings. The corrosion resistance of both coatings is very similar, as samples with both $\mathrm{Zn}$ and $\mathrm{Zn} / \mathrm{NP}$ coating were characterized by similar values of corrosion potential $\left(\mathrm{E}_{\mathrm{corr}}\right)$ and corrosion current density $\left(\mathrm{I}_{\mathrm{corr}}\right)$, as shown in Table 2 . 
This indicates that the addition of nanoparticles to the metal matrix does not compromise the anticorrosion properties as may happen in the case of microparticles [11]. The microscopic images of the surfaces of both coatings show numerous instances of corrosion discoloration, resulting from the area oxidation of the surface layer (Figure 2). However, further comparison of these images (Figure 2A,B) clearly reveals white rust on the $\mathrm{Zn}$ coatings. The corrosion products of $\mathrm{Zn} / \mathrm{NP}$ coatings are much less visible. This indicates that the inclusion of nanoparticles can slow down the corrosion process. The delay of white rust formation is the result of the enhanced barrier properties of nanocomposite coatings compared to pure zinc coatings.
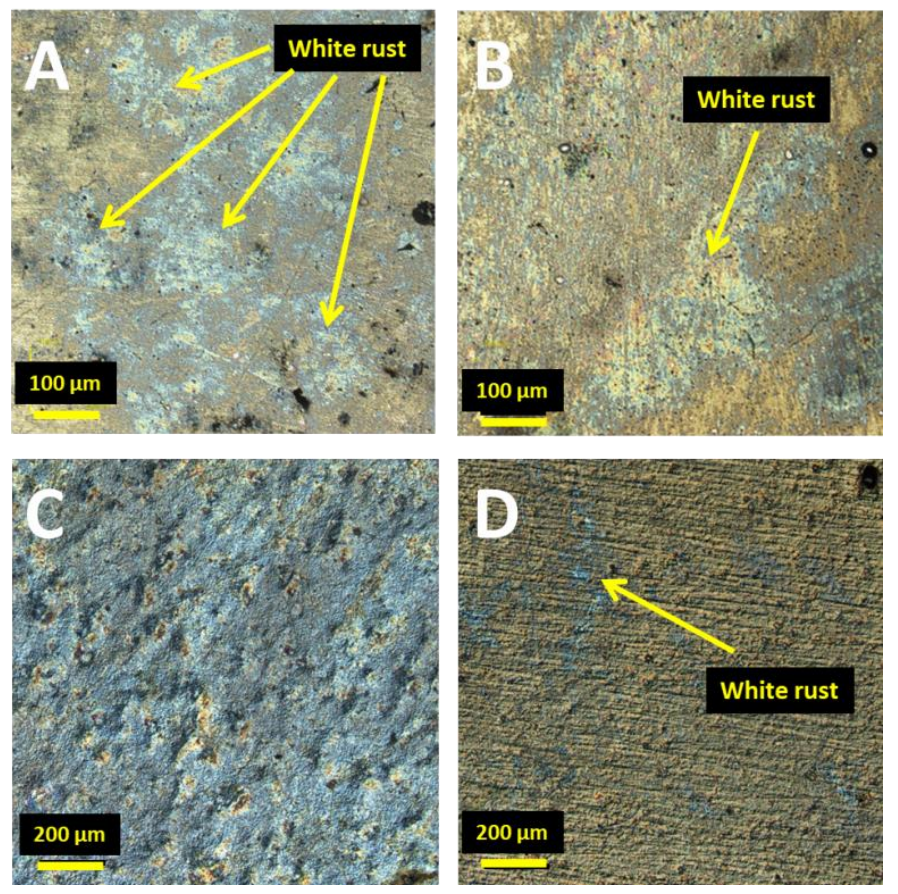

Figure 2. Images of surface morphology after electrochemical corrosion tests $(\mathbf{A}, \mathbf{B})$ and after six months of storage in a dry room $(\mathbf{C}, \mathbf{D})$. (A,C) Zn coatings; (B,D) Zn/NP composite coatings.

Furthermore, coated samples were stored for six months in a dry room at a constant temperature of $19-22{ }^{\circ} \mathrm{C}$. The microscopic analysis presented in Figure $2 \mathrm{C}$ showed that $\mathrm{Zn}$ coatings were all covered with white rust. For $\mathrm{Zn} / \mathrm{NP}$ composite coatings, the white rust phenomenon was much smaller and occurred locally (Figure 2D).

Analysis of resistance to motion after $300 \mathrm{~s}$ of friction shows that the kinematic pairs of $\mathrm{Zn}-\mathrm{Al}_{2} \mathrm{O}_{3}$, under non-lubricated conditions, were characterized by slightly higher friction coefficients at both $1 \mathrm{~N}$ and $2 \mathrm{~N}$ (Table 3). Lowering of the friction coefficient after adding the hard nanoparticles to the metallic coating was previously observed [12]. Increased resistance to motion resulted in deeper friction marks (Figure 3) and intensification of tribological wear (Figure 4). Comparison of the depth and volume of friction marks clearly indicates that the wear resistance of the pure $\mathrm{Zn}$ coating was rather weak. Significantly better tribological resistance was obtained when hard nanoparticles were incorporated into the zinc matrix ( $\mathrm{Zn} / \mathrm{NP}$ coatings). This may be due to the increased microhardness of $\mathrm{Zn} / \mathrm{NP}$ coatings, which was about $12 \mathrm{HV}$ higher than the $\mathrm{Zn}$ coatings. Additionally, it is suspected that during the friction process, the hard nanoparticles gradually protrude out of the zinc matrix and carry the load applied to the coating, resulting in the improved wear resistance of the nanocomposite coating. Roughness tests also indicated that $\mathrm{Zn} / \mathrm{NP}$ coatings were characterized by a higher roughness $\mathrm{Ra}(0.155 \pm 0.010 \mu \mathrm{m})$, which may have a slight impact on the higher resistance of motion in the first friction cycles. The results of roughness and microhardness measurements are presented in Table 4 . The increase of around $9 \%$ is a significant improvement in future applications of the nanocomposite coatings at an industrial scale. Images of selected friction traces are shown in Figure 5. 
Table 3. Values of coefficient of friction after $300 \mathrm{~s}$ of cycles.

\begin{tabular}{ccc}
\hline Sample & Fn $=\mathbf{1} \mathbf{~ N}, \mathbf{f}=\mathbf{5} \mathbf{~ H z}$ & Fn $=\mathbf{2 ~ N}, \mathbf{f}=\mathbf{1 0 ~} \mathbf{~ z z}$ \\
\hline Zn & $0.79 \pm 0.06$ & $0.85 \pm 0.06$ \\
Zn/NP & $0.68 \pm 0.08$ & $0.80 \pm 0.04$ \\
\hline
\end{tabular}
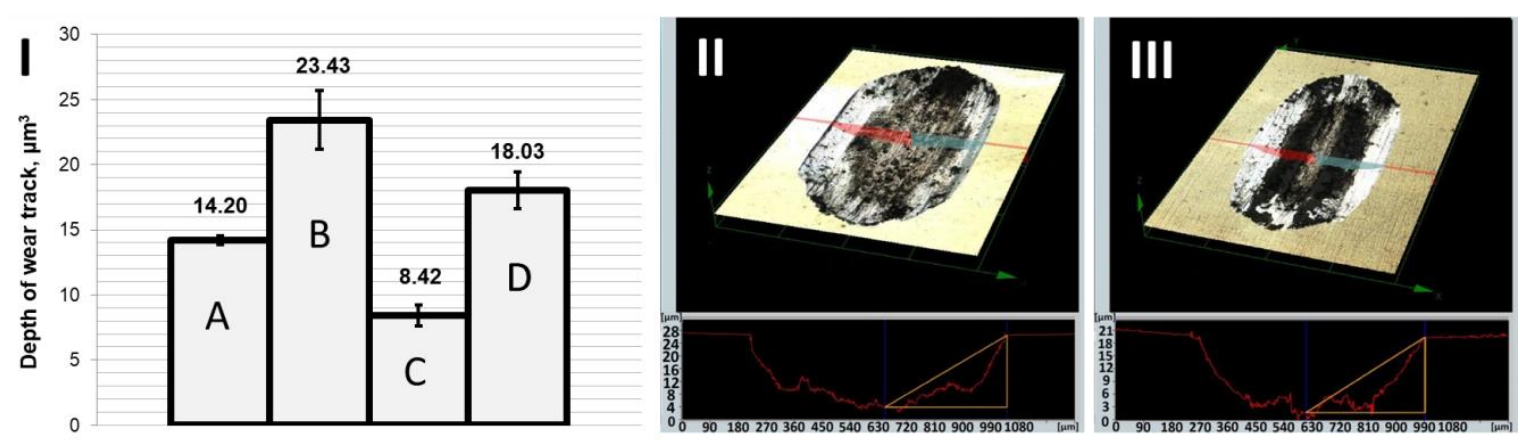

Figure 3. (I) Depth of the friction marks for: A-Zn coating at Fn $=1 \mathrm{~N}, \mathrm{f}=5 \mathrm{~Hz} ; \mathrm{B}-\mathrm{Zn}$ coating at $\mathrm{Fn}=2 \mathrm{~N}, \mathrm{f}=10 \mathrm{~Hz} ; \mathrm{C}-\mathrm{Zn} / \mathrm{NP}$ coating at $\mathrm{Fn}=1 \mathrm{~N}, \mathrm{f}=5 \mathrm{~Hz} ; \mathrm{D}-\mathrm{Zn} / \mathrm{NP}$ coating at $\mathrm{Fn}=2 \mathrm{~N}, \mathrm{f}=10 \mathrm{~Hz}$. (II) image of sample B. (III) image of sample D.
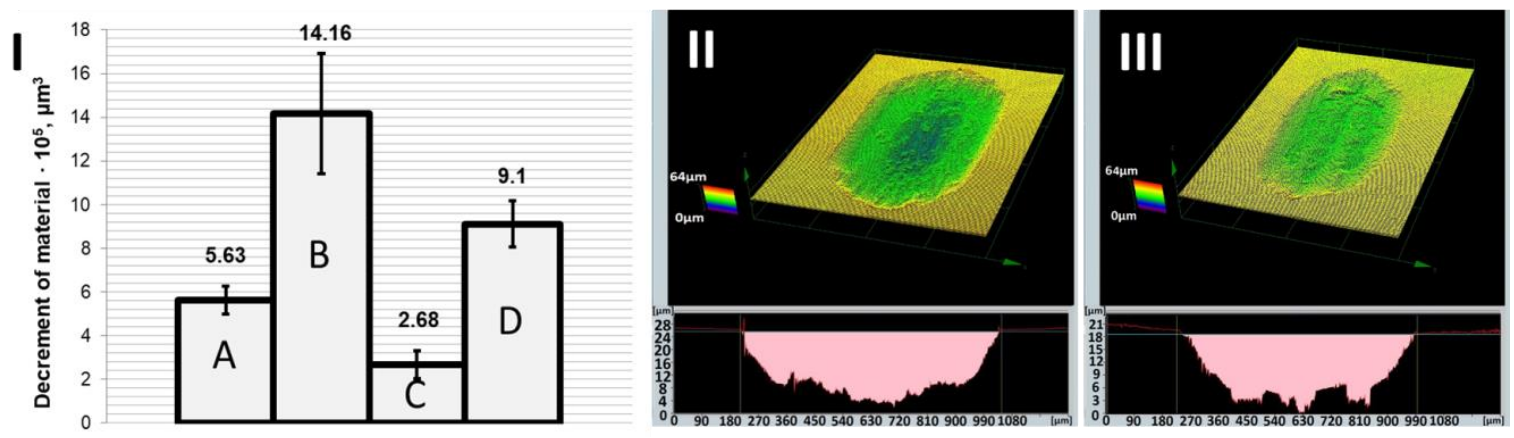

Figure 4. (I) Volume of friction marks for: A-Zn coating for $\mathrm{Fn}=1 \mathrm{~N}, \mathrm{f}=5 \mathrm{~Hz}$; B-Zn coating for $\mathrm{Fn}=2 \mathrm{~N}, \mathrm{f}=10 \mathrm{~Hz} ; \mathrm{C}-\mathrm{Zn} / \mathrm{NP}$ coating for $\mathrm{Fn}=1 \mathrm{~N}, \mathrm{f}=5 \mathrm{~Hz} ; \mathrm{D}-\mathrm{Zn} / \mathrm{NP}$ composite coating for Fn $=2 \mathrm{~N}$, $\mathrm{f}=10 \mathrm{~Hz}$. (II) Image of sample B. (III) Image of sample D.

Table 4. Values of microhardness and roughness of tested surfaces.

\begin{tabular}{ccc}
\hline Sample & Microhardness $\mathbf{H V}_{\mathbf{0 . 1}}(\mathbf{G P a})$ & Roughness Ra $(\boldsymbol{\mu m})$ \\
\hline Zn & $112 \pm 1.17$ & $0.143 \pm 0.053$ \\
Zn/NP & $124 \pm 2.96$ & $0.155 \pm 0.010$ \\
\hline
\end{tabular}

The tribological studies are summarised in Tables 3 and 4 and Figures 3 and 4 .

The microscopic analysis of friction marks presented in Figure 5 shows that wear debris accumulated on the surface as a result of sliding. Therefore, remaining in the wear area, these scraps led to intensification of second wear processes. A larger amount of wear products was generated for Zn coatings, which is particularly evident in the photos taken with the SEM technique (Figure 5A,C). It should be noted that the higher hardness of $\mathrm{Zn} / \mathrm{NP}$ coatings affected their brittleness. At the edges of contact of the surface with the alumina ball, delamination, cracking and chipping of the applied coating occurred, especially in the case of samples subjected to friction processes at normal force $\mathrm{Fn}=2 \mathrm{~N}$ and frequency $\mathrm{f}=10 \mathrm{~Hz}$ (Figure 5D). The abrasion of $\mathrm{Zn}$ coatings occurred rather uniformly (Figure 5C).

Traces of friction were also tested with energy dispersive X-ray spectroscopy (EDS). Selected test results are presented in Figure 6. 

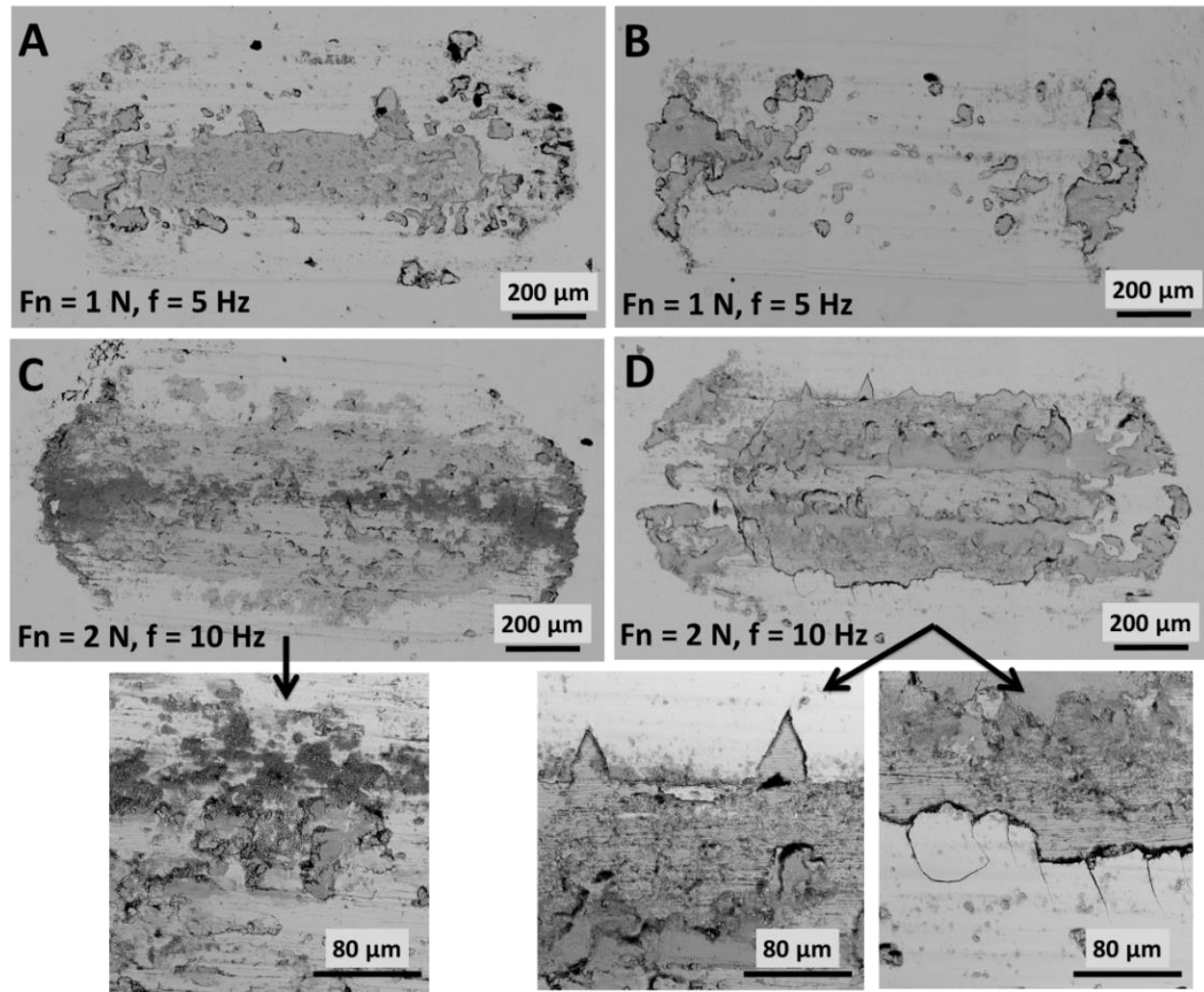

$200 \mu \mathrm{m}$

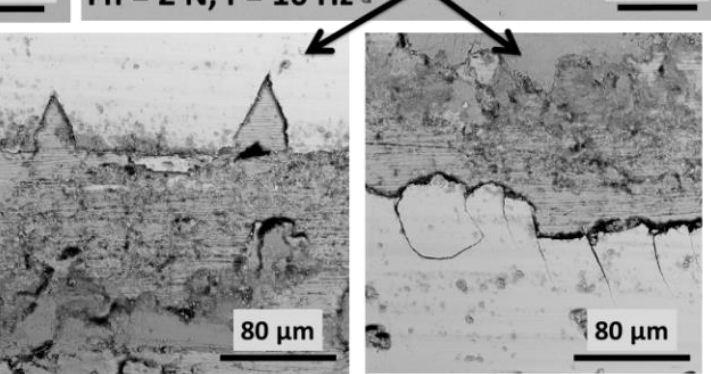

Figure 5. SEM images of wear tracks: $(\mathbf{A}, \mathbf{C}) \mathrm{Zn}$ coating; (B,D) Zn/NP coating, tested with the following parameters: normal force $(\mathrm{Fn})=1 \mathrm{~N}$, frequency $(\mathrm{f})=5 \mathrm{~Hz}$ (top) and normal force $(\mathrm{Fn})=2 \mathrm{~N}$, frequency (f) $=10 \mathrm{~Hz}$ (bottom).
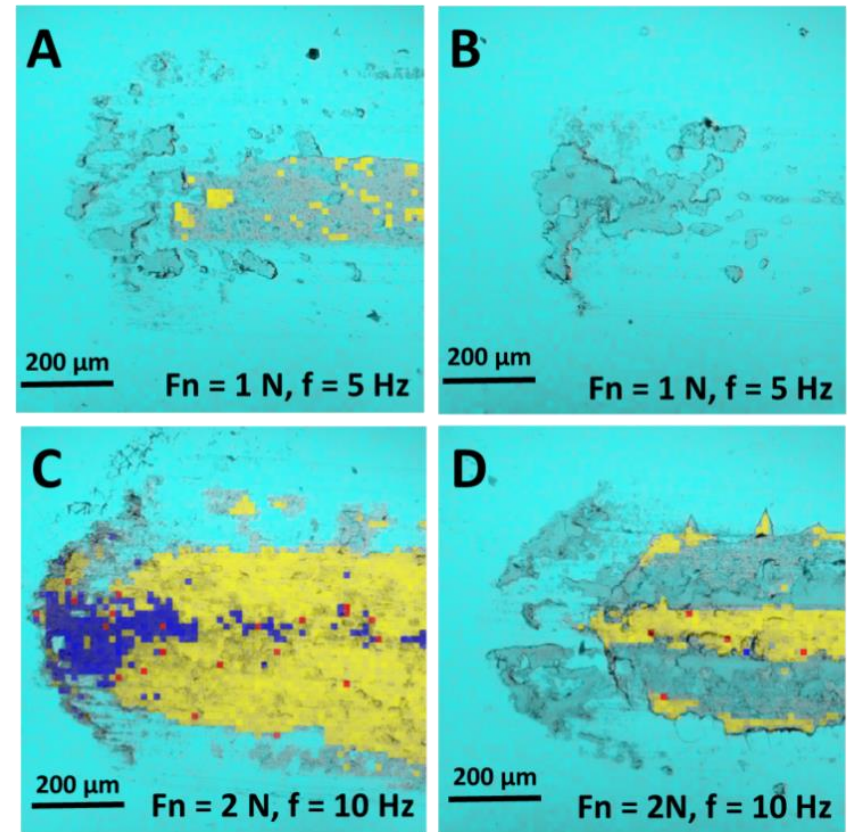

\section{Main element}

\section{$\mathrm{Zn}$}

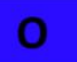

Fe

$\mathrm{Cr}$

Figure 6. Energy dispersive $X$-ray spectroscopy (EDS) test results for coated samples: (A,C) Zn; (B,D) Zn/NP tested with the following parameters: normal force $(\mathrm{Fn})=1 \mathrm{~N}$, frequency $(\mathrm{f})=5 \mathrm{~Hz}$ (top) and normal force $(\mathrm{Fn})=2 \mathrm{~N}$, frequency $(\mathrm{f})=10 \mathrm{~Hz}$ (bottom).

X-ray analysis of the elemental composition of the surfaces of samples subjected to friction processes confirms the increased tribological strength of $\mathrm{Zn} / \mathrm{NP}$ coatings. At lower unit loads at the 
friction site, the coating core was not exposed (Figure 6B). With similar friction parameters for $\mathrm{Zn}$ coatings, places where iron quantitatively predominated were visible (Figure 6A), which suggests a gradual exposure of the material core. The increase in unit load and the friction frequency intensified tribological wear processes, which was the highest for samples with Zn coating. EDS analysis has shown that wear products consisting mainly of oxygen and iron were moved to the edges of the friction zone (Figure 6C). The amount of collected particles was smaller for samples with $\mathrm{Zn} / \mathrm{NP}$ coatings (Figure 6D).

\section{Conclusions}

Zinc and zinc nanocomposite coatings were successfully prepared by electrodeposition from the widely used commercial acidic bath. Nanoparticles were introduced into the coating by applying the plating additive provided by Coat-It Sp. z o. o., which allowed for the straightforward production of the nanocomposite coatings. No additional processes and components were required. The tribological study of these coatings suggested a notable increase in the wear resistance of the nanocomposite coatings. The $\mathrm{Zn}$ nanocomposite coating also exhibited higher hardness. Electrochemical studies of corrosion resistance revealed similarity in response for both types of coatings. However, nanocomposite coatings showed a delay in the formation of white rust. This could lead to the enhancement of the Zn nanocomposite coating service life. We plan to optimise the coating composition, which will help to improve the nanocomposite coatings' properties even further. This study highlights the use of nanoparticles for the control of zinc coating corrosion and mechanical properties. The method of adding nanoparticles could be used to generate zinc nanocomposite coatings in the plating industry. It was also shown that CLSM is a complementary technique that can be applied to study the tribological properties of traditional and composite coatings.

Author Contributions: Conceptualization, M.K. (Marcin Klekotka), A.S., and M.K. (Michal Kuciej); methodology, M.K. (Marcin Klekotka) and K.Z.; validation, M.K. (Marcin Klekotka), A.S., and K.Z.; formal analysis, K.Z. and A.S.; investigation, M.K. (Marcin Klekotka); resources, M.K. (Marcin Klekotka) and A.S.; writing-original draft preparation, M.K. (Marcin Klekotka); writing_review and editing, A.S., K.Z., M.K. (Michal Kuciej), and M.K. (Marcin Klekotka); visualization, M.K. (Marcin Klekotka); supervision, M.K. (Michal Kuciej); project administration, M.K. (Michal Kuciej); funding acquisition, M.K. (Michal Kuciej). All authors have read and agreed to the published version of the manuscript.

Funding: This study was performed within the framework of project "Start-up platforms the new ideas-Hub of Talents 2" realized by the City of Białystok-Białystok Science and Technology Park and co-financed by the European Union within the framework of the European Regional Development Fund under Priority Axis I: Entrepreneurial Eastern Poland, Action 1.1 Start-up platforms for new ideas, Sub-action 1.1.1 Start-up platforms for new ideas of the Operational Programme Eastern Poland 2014-2020 (OP EP), and project financing through the program of the Minister of Science and Higher Education of Poland named "Regional Initiative of Excellence" in 2019-2022, project No. 011/RID/2018/19, amount of financing 12,000,000 PLN.

Conflicts of Interest: The authors declare no conflicts of interest.

\section{References}

1. Praveen, B.M.; Venkatesha, T.V. Electrodeposition and properties of $\mathrm{Zn}$-nanosized $\mathrm{TiO}_{2}$ composite coatings. Appl. Surf. Sci. 2008, 254, 2418-2424. [CrossRef]

2. Ayoola, A.A.; Fayomi, O.S.I.; Popoola, A.P.I. Anticorrosion properties and thin film composite deposition of Zn-SiC-Cr ${ }_{3} \mathrm{C}_{2}$ coating on mild steel. Def. Technol. 2019, 15, 106-110. [CrossRef]

3. Muller, C.; Sarret, M.; Garcia, E.; Ortega, J.A. Cr-Free Passivation on ZnNi Alloys. J. Electrochem. Soc. 2004, 151, 149. [CrossRef]

4. Muresan, L.M. Handbook of Nanoelectrochemistry; Springer International Publishing: Cham, Switzerland, 2015.

5. Mokabber, T.; Rastegari, S.; Razavizadeh, H. Effect of electroplating parameters on properties of $\mathrm{Zn}-\mathrm{nano}-\mathrm{TiO} \mathrm{O}_{2}$ composite Coatings. Surf. Eng. 2013, 29, 41-45. [CrossRef]

6. Min, C.; He, Z.; Song, H.; Liu, D.; Jia, W.; Qian, J.; Jin, Y.; Guo, L. Fabrication of novel CeO $2 /$ GO/CNTs ternary nanocomposites with enhanced tribological performance. Appl. Sci. 2019, 9, 170. [CrossRef] 
7. Kammona, O.; Kotti, K.; Kiparrisides, C.; Celis, J.P.; Fransaer, J. Synthesis of polymeric and hybrid nanoparticles for electroplating applications. Electrochim. Acta 2009, 54, 2450-2457. [CrossRef]

8. Mohammadnejad, M.; Habibolahzadeh, A.; Yousefpour, M. Effect of Nano Oxide Addition on Corrosion Performance of Hot Dip Zinc Coating. Pot. Met. Phys. Chem. 2016, 52, 100-103. [CrossRef]

9. Conrad, H.; Golden, T. Electrodeposited Zinc-Nickel Nanocomposite Coatings. In Nanocomposites-Recent Evolutions; IntechOpen: London, UK, 2018.

10. Dabrowski, J.R.; Klekotka, M.; Sidun, J. Fretting and fretting corrosion of 316L implantation steel in the oral cavity environment. Eksploat. i Niezawodn. Maint. Real. 2014, 16, 441.

11. Praveen, B.M.; Venkatesha, T.V.; Arthoba Naik, Y.; Prashantha, K. Corrosion studies of carbon nanotubes Zn composite coating. Surf. Coat. Technol. 2007, 201, 5836-5842. [CrossRef]

12. Fayomi, O.S.I.; Popoola, A.P.I.; Loto, C.A. Tribo-mechanical investigation and anti-corrosion properties of $\mathrm{Zn}-\mathrm{TiO}_{2}$ thin film composite coatings from electrolytic chloride bath. Int. J. Electrochem. Sci. 2014, 9, 3885-3903.

(C) 2020 by the authors. Licensee MDPI, Basel, Switzerland. This article is an open access article distributed under the terms and conditions of the Creative Commons Attribution (CC BY) license (http://creativecommons.org/licenses/by/4.0/). 